\title{
O DIREITO É AUTOPOIÉTICO? PONDERAÇÕES ACERCA DO PENSAMENTO SISTÊMICO LUHMANNIANO
}

\section{LE DROIT EST AUTOPOÏETIQUE? POIDS SUR LA PENSEE SYSTEMIQUE LUHMANNIAN}

\author{
Christie Danielle Sikorski*
}

\begin{abstract}
RESUMO
A teoria dos sistemas de Niklas Luhmann apresenta-se como uma complexa corrente doutrinária. Estudá-la e compreendê-la é de fundamental importância para correlacioná-la ao Direito, enquanto sistema social. O presente artigo tem por objetivo responder ao irrequieto questionamento: o Direito é autopoiético? Para elucidar a questão, o texto além de trazer breves comentários acerca da vida e obra de Luhmann, aborda a teoria sistêmica, sem, no entanto, esgotar a matéria. Posteriormente, analisa o Direito, a ligação deste com a referida teoria e expõe a visão do autor tangente à Constituição.
\end{abstract}

Palavras-chave: Teoria dos Sistemas. Direito. Autopoiese. Constituição.

\section{RESUMÉ}

La Théorie des Systèmes de Niklas Luhmann se présente comme une doctrine complexe actuel. Létudier et à comprendre qu'il est d'une importance fondamentale pour elle en matière de Droit comme un système social. Cet article vise à répondre à la question en suspens: le Droit est autopoḯtique? Afin de clarifier la question, le texte en plus de fournir de brefs commentaires sur la vie et l’ouvre de Luhmann, traite de la Théorie Systémique, sans toutefois épuiser le sujet. Plus tard, il analyse le Droit, ce lien avec cette théorie et expose la vision de l'auteur sur la Constitution.

Mots-clés: Théorie dês Systèmes. Droit. Autopoiesis. Constituition. 


\section{Introdução}

O reconhecimento que a Teoria dos Sistemas de Niklas Luhmann em muito contribuiu para o Direito é ponto comum entre os mais diversos doutrinadores. Visionário sociólogo, por meio de expressiva forma de entender o Direito, inseriu-o em sua estrutura sistêmica, perpassou os conceitos até então arraigados, rompeu-os e fez história.

Cumpre registrar que o interesse na temática desta pesquisa teve origem a partir do primeiro contato com a Teoria dos Sistemas, quando inserida no programa de Mestrado. Assim, o estudo desenvolveu-se no intuito de entender a intrigante forma de pensar de Niklas Luhmann.

A Teoria dos Sistemas surge para inutilizar as premissas clássicas apresentando um design teórico para ocupar o lugar das mesmas. (NEVES, 1997).

Em contraponto, não busca soluções práticas, mas sim produzir formulações conceituais aplicáveis à realidade empírica. Por oportuno, efetivar a análise desta teoria mostra-se de suma importância para compreender a sociedade moderna, o Direito e o objeto que aqui se estuda.

Este artigo tem como objeto geral a Teoria dos Sistemas luhmanniana e a correlação desta com o Direito. Já, como objeto específico, utilizar o acervo teórico da teoria sobredita a fim de responder a seguinte questão: o Direito é autopoético?

Entretanto, como todos os campos acima mencionados são amplos e complexos, seria impossível reduzi-los, ou ainda, tentar explaná-los em um único texto.

Assim, para chegar ao foco principal deste estudo, no primeiro momento, se faz uma contextualização história acerca da vida e obra de Luhmann.

Por conseguinte, apresenta-se uma análise sobre a teoria sistêmica de Niklas, apontando fases, conceitos e pressupostos fundamentais no intuito de delinear uma visão panorâmica da mesma.

No arremate, trata-se acerca do Direito e da Constituição, correlacionado-os à teoria exposta, bem como responde-se ao questionamento tangente à ligação entre ambos qual seja, se é possível considerar o Direito como um sistema autopoiético.

Justifica-se o presente trabalho pois referidas questões evidenciam-se importantes na medida em que sua compreensão formam, não raras vezes, a base dos estudiosos e operadores do Direito, e identificá-las, facilita a dialética entre a prática e a teoria.

Neste trabalho a metodologia amparouse em pesquisa bibliográfica através de diversos doutrinadores.

\section{Niklas Luhmann: contextualização histórica}

Sociólogo alemão, nasceu em 1927 e faleceu em 1998. Estudou Direito em Freiburg, no período compreendido entre 1946 a 1949. Logo após, mais precisamente entre 1956 a 1962, atuou como assessor no Ministério da Educação e Ciência. Ainda, no ano de 1960, trabalhou com Talcott Parsons em Harvard, quando teve o primeiro contato com a Teoria dos Sistemas. Devido a esta aproximação com Parsons é que Niklas começou a estudar a Teoria dos Sistemas, efetivamente, a qual serviu como incentivo à elaboração de sua própria teoria; entretanto, cabe pontuar, com caracteres distintos.

Em 1962, retorna à Alemanha e labora como assessor em cargo administrativo. Helmunt Schelzky, também sociólogo alemão, foi quem incentivou Luhmann a seguir carreira universitária, e isto deu-se em 1965.

Após concluir doutorado, assumiu, em 1968, a cátedra de Sociologia na Universidade de Bielefeld, onde permaneceu até 1993. Neste período, desenvolveu a Teoria dos Sistemas e consolidou-a em inúmeras obras.

Aposentou-se aos 65 anos, fato que não obstou a continuidade de pesquisa e produção nas mais diversas áreas, tais como: religião, economia, direito, pedagogia, entre outras. (NEVES, 1997).

AobradeLuhmann, emboratenhasido, àépoca, muito criticada, vez que entendia ser necessário um estudo específico das realidades sociais, que estavam, a cada dia, mais complexas; passou a ter importância na medida em que foi reconhecido o déficit da teoria sociológica para compreender a sociedade, que evolui constantemente. (NEVES, 1997).

Neste contexto, torna-se importante definir o termo complexidade, que, segundo Mariotti, corresponde à multiplicidade, ao entrelaçamento e à contínua interação da infinidade de sistemas 
e fenômenos que compõem o mundo natural. (MARIOTTI, 2000).

Sobre o tema em voga, pontua Clarissa Neves (1997, p.11): “A sociedade moderna, preocupação central de Luhmann, tem como características principais a complexidade e a diferenciação funcional".

Extrai-se do pensamento luhmanniano que não é possível analisar todos os fenômenos sociais tomando por base apenas uma única teoria. (LUHMANN, 2011). Ora, se no mundo social ocorrem alterações tão rápidas que as teorias tradicionais não podiam explicá-las, e com Luhmann, tem-se esta possibilidade; nada mais justo que estudar esta nova teoria, valorizando-a.

Assim, segue exposta, em breves comentários, a Teoria Sistêmica de Luhmann: suas fases, conceitos e pressupostos fundamentais, haja vista ser essencial este entendimento teórico; para, então, evidenciar a correlação com o foco central deste artigo. Ademais, cabe pontuar que neste texto não se pretende exaurir o assunto, mas sim acirrar a discussão acerca da supracitada teoria.

\section{Teoria dos sistemas: fases, conceitos e pressupostos fundamentais}

Incorporando o posicionamento de Neves (1997, p. 10), a obra de Luhmann pode ser considerada como um esforço em formular uma teoria à sociedade em que busca-se um aporte universal que supere a estreiteza da conexão entre o micro e o macro.

O marco de partida é a redução da complexidade da sociedade por meio do sistema, e neste ínterim, como é possível a ordem surgir do caos.

No sistêmico modo de pensar, tem destaque especial a interdisciplinaridade, a qual pode ser definida como a troca de metodologia e fontes de uma disciplina para outra. (SEVERINO, 2000).

Traz, a história, que na Antigüidade Clássica poderia ser observada uma distinção, por exemplo, entre gregos e bárbaros. Existia, então, um referencial único, que distinguia e sintetizava todos os reflexos produzidos nos mais diversos contextos, quer sejam sociais, políticos, econômicos, jurídicos, entre outros. (PEDRON, 2004).

Atualmente, esta forma de separação não é mais possível, vez que há uma ligação entre a implementação de um período de complexidades ímpares com a entrada da sociedade para a modernidade, de forma especial, a partir do desenvolvimento da concepção de indivíduo.

Luhmann estudou a sociedade moderna, que é divida por funções e não somente por hierarquização de classes.

Para Niklas, não existe apenas uma hierarquia, mas sim funções diferenciais independentes manifestas por meio da comunicação - que tornam a sociedade bastante complexa, portanto, minorar esta complexidade é função fundamental do sistema social. (LUHMANN, 2011)

Assim, cumpre dizer que o caráter de universalidade da teoria dos sistemas rompeu com os modelos até então existentes. Da mesma forma, com a proposta de interação das várias áreas científicas, a teoria pretende servir como instrumento à elaboração de uma teoria geral da sociedade. (NEVES, 1997).

Segundo Neves (1997, p. 11): a teoria compreende os diferentes tipos de sistemas, bem como as condições distintivas de cada um. E mais, apresenta-se como um poderoso instrumental analítico que permite a compreensão do funcionamento da sociedade e de seus subsistemas - direito, política, economia, religião, entre outros - cada qual, operando por meio de um código próprio, que permite sua identificação e singularização.

Via de consequência, só é possível entender e reduzir esta complexidade a partir de sistemas tão complexos quanto, e nas palavras de Neves (1997, p.11):

O centro do interesse de Luhmann é portanto compreender a complexidade da sociedade moderna. E essa sociedade complexa, multifuncionalmente diferenciada, precisa a seu ver de uma abordagem adequada, igualmente complexa.

Para tanto, é condição essencial a superação de três obstáculos epistemológicos, quais sejam: preconceito humanista (pelo qual a sociedade é constituída de pessoas ou de relações entre estas, e que as mesmas são partes dos sistemas sociais); o preconceito das unidades ou fronteiras territoriais (pelo qual as fronteiras das sociedades são políticas e/ou territoriais); e o preconceito da objetividade social (pelo qual se concebe a separação entre sujeito e objeto). (NEVES, 1997). 
Desta feita, Luhmann, adepto de uma forma particularmente própria do pensamento sistêmico, teorizou-o como autopoiético, fazendo uma transposição da realidade vivenciada para sua teoria, que pode ser dividida em fases/períodos, que seguem explanados.

\subsection{Fases da Teoria Sistêmica}

A obra de Niklas pode ser dividida em duas fases.

A primeira fase compreende o período entre as décadas 60 e 80, durante o qual a teoria de sistemas era estrutural-funcional, aberta, tendo por base a diferença entre sistema e seu entorno, ou seja, seu ambiente. (NEVES, 1997).

Na relação entre sistema e ambiente, ambos se determinam, um em diferenciação ao outro: o que faz parte do sistema e o que não faz parte do sistema, mas sim, do entorno. De acordo com Luhmann (2011, p.20):

Estes contornos conceituais referem-se a operações que transcorrem realmente, com as quais o sistema reproduz-se a si mesmo, assim como sua diferenciação em relação ao ambiente.

Entretanto, permanecia uma lacuna teórica, posto que, embora para Niklas tudo o que existisse estivesse abrangido pela teoria, somente poderia estar na condição de sistema ou de ambiente.

Assim, em 1984, restou evidente a necessidade de releitura da forma de pensamento e análise até então postas, quando teve início a segunda fase, na forma fechada, com a publicação da obra "Sistema Social, esboço de uma teoria geral”. (NEVES, 1997).

Neste período surgiu a autopoiésis, mediante a qual os sistemas geram e reproduzem internamente seus próprios elementos de funcionamento sem a influência de elementos externos. Nas palavras de Luhmann (2011, p.21):

Contudo, se todo o conhecimento precisa ser alcançado com base na distinção entre autorreferência e heterorreferência, isto é o mesmo que dizer que todo o conhecimento (e, com isto, toda a realidade) é uma construção. Pois esta distinção entre autorreferência e heterorreferência não pode estar no ambiente externo do sistema (o que seria aí o "auto-" e o que seria aí o "hétero-"?), mas no próprio sistema.
De acordo com este novo posicionamento, os sistemas não podem ser determinados por meio dos acontecimentos provenientes do ambiente. Dito isso, é necessário dispor, com maior especificidade, acerca dos temas sistema e ambiente.

\subsection{Relação entre Sistema e Ambiente}

Os sistemas têm a função de captar e reduzir a complexidade do mundo. Não é tudo que existe no ambiente que integra o sistema; portanto, somente é possível constituir sistema a partir da diferenciação com o seu entorno.

Sistema, para Chaí (2004, p.50) é: "um conjunto de elementos inter-relacionados, cuja unidade é dada por suas interações e cujas propriedades são distintas deste elemento". Já, para Luhmann apud Neves (1997, p.11): "sistema é o mediador entre a extrema complexidade do mundo e a pequena capacidade do homem em assimilar as múltiplas formas de vivência".

Ademais, na opinião do autor, a fim de reduzir esta complexidade o sistema desenvolve estratégias e duas são fundamentais, quais sejam: transposição de problemas (com a qual se dá a redefinição do problema da complexidade do mundo em problema do sistema, sob três dimensões: temporal, objetiva e social), e dupla seletividade (pela qual se procede a seleção progressiva das possibilidades do mundo, ordenando-as em forma de um código significativo).

$\mathrm{Na}$ primeira fase, considera os sistemas sociais como uma conexão de sentido de ações sociais, onde o meio é elemento de referência do sistema; e trata o homem também como meio. Entende, neste período, que os sistemas sociais dividem-se em três: interação (que diz respeito ao contato entre as pessoas); organizacionais (os quais são definidos por regras de pertencimento) ou societais (relacionadas à sociedade) .

Já, na segunda fase, produz novos conceitos e supera obstáculos epistemológicos, ao entender que não é possível aplicar conceitos tradicionais aos problemas fundamentais da sociedade contemporânea. Assim, o sistema autopoiético se define por sua diferença com relação ao meio, ou seja, é preciso analisar, entender e considerar esta diferença.

Para Niklas, existem três tipos de sistemas autopoiéticos, quais sejam: sistemas vivos (referentes 
as operações vitais), sistemas psíquicos (referentes a consciência) e sistemas sociais (relativos as comunicações). Não obstante, posiciona-se no sentido de que os sistemas sociais são comunicativos e reproduzem-se por estarem ligando comunicações às comunicações. (NEVES, 1997).

Ponto de bastante relevância e que merece especial destaque ao estudar Luhmann é evidenciar a superação de alegações surgidas à época, haja vista que não considera o homem como centro do sistema social, pelo contrário, descarta a existência deste dentro do sistema. E mais, profere que os seres humanos - sistemas autorreferentes - são o meio da sociedade e não componentes daquela.

Por fim, diz que o sistema social é composto de comunicação e não de pessoas; e tudo encontra-se integrado ao ambiente, cuja característica comum aos mesmos é serem: autopoiéticos, autorreferentes e operacionalmente fechados. (LUHMANN, 2011).

\subsection{Autopoiesis}

O termo autopoiese é grego, em que auto significa próprio e poiesis, criação. Assim, o sentido literal é auto-fazer(se) ou auto-produzir(se).

Este termo, originário da biologia, foi cunhado na década de 70, por Francisco Varela e Humberto Maturana, para designar a capacidade dos seres vivos de produzirem a si próprios. Posteriormente, a construção conceitual difundiu-se e passou a ser aplicada em outras áreas do conhecimento, até, finalmente, ser amplamente utilizada na seara das Ciências Sociais.

Vale dizer que falar em autopoiese não é falar somente em autorreferência, mas principalmente é tratar dos processos que formam o ser como uma unidade. Ademais, a conservação da autopoiese e da adaptação do ser vivo ao seu meio são condições sistêmicas para a vida e, nas palavras de Maturana (1995, p. 84): “... os seres humanos se caracterizam por literalmente, produzirem-se continuamente a si mesmos, o que indicamos ao chamarmos a organização que os define de organização autopoiética".

No esteio deste pensamento, é importante registrar que o conceito de autopoiese enfatiza o fato dos seres vivos serem unidades autônomas. É, pois, a autopoiese que lhes confere esta característica própria. Neste sentido, diz Maturana (1995, p.88):
"Tomar consciência dos seres vivos como unidades autônomas (...) se torna explícito quando indicamos que aquilo que os define como unidade é sua organização autopoiética".

De acordo com esta teoria todo ser vivo é um sistema autopoiético e caracteriza-se como uma rede fechada de processos moleculares, nos quais as moléculas produzidas geram - com suas interações - a mesma rede de moléculas que as produziu.

Por outro lado, tem-se que o ambiente pode irritar o sistema, estimulando a autoprodução, entretanto, este fato ocorre tão somente quando o próprio sistema seleciona as possibilidades insertas no entorno.

Há que se conservar a autopoiese, bem como adaptá-la ao meio, pois são as condições impostas pelo sistema. Desta feita, todo sistema (exceto o não-vivo), está se autoproduzindo e autorregulando constantemente, haja vista que é ele próprio que formula as lógicas necessárias de sua operação.

Segundo a perspectiva de Varela apud Correia, exposta no texto "Os mass media entre o sistema e o mundo da vida", pode-se dizer que um sistema é autopoiético quando organizado por uma rede de processos de produção de componentes ao tal ponto que estes regenerem a rede que o produziu de forma continuada.

No dizer de Luhmann (2011, p. 30):

O sistema pressupõe-se a si mesmo como irritação autoproduzida, sem ser atingível por meio de suas próprias operações, e então ocupa-se com a transformação de irritação em informação que ele produz para a sociedade(e para si mesmo na sociedade).

Contudo, cabe ressaltar que existe uma diferença entre a concepção de autopoiese para Luhmann e para Maturana/Varela, na medida em que, enquanto estes restringem a aplicação da construção aos sistemas vivos, Luhmann aplica-os também aos sistemas sociais e psíquicos.

A respeito, diz Luhmann apud Fedozzi (1997, p. 23-27): a partir do paradigma da autorreferência a vida pode ser considerada como uma organização autorreferencial (no sentido de que a sua ordem interna é gerada a partir da interação dos seus próprios elementos) e autorreprodutiva (no sentido de que tais elementos são produzidos a partir dessa mesma rede de interação circular e recursiva). 
Portanto, "com base em sua diferenciação fechada em si mesma, o sistema pode considerar a si mesmo, sua própria função, sua própria prática como ponto de referência para a especificação de suas próprias operações". (LUHMANN, 2011, p. 50).

Nesta linha de pensamento cabe consignar que, pela autopoiesis, o sistema complexo reproduz seus elementos dentro de uma construção fechada, por meio de seus próprios elementos, dependendo, para tanto, das operações internas e anteriores do mesmo sistema. Por conseguinte, determina-se, por óbvio, o acoplamento estrutural e assim caracteriza-se o fechamento operacional, base da autonomia deste mesmo sistema.

\subsection{Comunicação}

A partir do delineamento acima exposto, bem como dos conceitos já colacionados, chega-se ao último elemento e ponto principal da teoria de Luhmann: a comunicação.

Uma comunicação ocorre "quando alguém vê, ouve, lê - e entende que daí se depreende uma outra comunicação que pode seguir-se a essa". (LUHMANN, 2011, p. 19).

Seguindo este entendimento, afirma Luhmann (2011, p.15):

Aquilo que que sabemos sobre nossa sociedade, ou mesmo sobre o mundo no qual vivemos, o sabemos pelos meios de comunicação. Isto vale não apenas para nosso conhecimento da sociedade e da história, mas também para osso conhecimento da natureza.

Comunicação é operação social. Independe do homem. Ocorre quando há compreensão da informação por aqueles que se comunicam. Não obstante, conclui-se que cada comunicação pode gerar, ou não, uma nova comunicação.

Para Luhmann, a comunicação ocorre com a sintetização da informação, da mensagem e da compreensão. Portanto, quando as comunicações ligam-se as comunicações, é que caracteriza-se a autopoiese do sistema. (NEVES, 1997).

Há que se pensar, segundo Luhmann (2011, p.130): "no conhecimento do mundo que o sistema dos meios de comunicação produz e reproduz".

Por sua vez, Correia ao referenciar Luhmann, diz: ...a sociedade é somente composta de comunicações (e não de homens) e tudo o que não é comunicação pertence ao ambiente do sistema... Tudo o que existe que se pode designar como social resulta de um tipo de acontecimento: a comunicação.

Deduz-se, ainda, que a comunicação une os sistemas e garante a escolha dos elementos que farão parte do mesmo, através da linguagem.

Neste sentido: os sistemas sociais são sistemas de comunicação, dos quais - a sociedade - é o mais abrangente. E mais, cada sistema é definido pela fronteira entre ele mesmo e o ambiente, separando-o de um exterior infinitamente complexo.

Em suma, resta sintetizada a teoria luhmanniana, que é de significativa importância para entender a sociedade moderna, haja vista a premente necessidade de avaliá-la como um todo e não somente em departamentos ou setores. Não menos importante, é fazer a correlação daquela ao Direito, em seu viés normativo.

Por derradeiro, exarados os pressupostos e conceitos básicos da teoria dos sistemas de Luhmann, avança-se no presente artigo, no intuito de dispor sobre o Direito, enquanto sistema social.

\section{Direito, constituição e a correlação à teoria Luhmanniana}

Neste ponto do trabalho frisa-se que o foco não é tratar sobre o positivismo do Direito ou da Constituição, mas sim relacioná-los à teoria sistêmica de Niklas Luhmann.

O Direito é um subsistema dentro do sistema social e desempenha sua função por meio de seu código binário lícito/ilícito. Para Luhmann, por ser a base da ordem social garante um patamar mínimo de orientação de condutas. (LUHMANN, 1983).

Não há como cogitar a existência da sociedade, tampouco do sistema social, sem ordenamento, sem o Direito. É importante salientar que o Direito mantém uma interdependência, ou seja, um acoplamento estrutural recíproco com a sociedade, sendo imprescindível àquela, na medida em que constitui parte da sociedade e estrutura do sistema social.

Sua dualidade de oposição tem dupla função, quais sejam: reduzir a complexidade da sociedade, reestruturando-a por meio de seu código e tornála apta a alcançar a complexidade estruturada. $\mathrm{Na}$ 
concepção de Niklas o Direito é uma construção de alta complexidade estruturada. (LUHMANN, 1983).

Não se pode admitir a ideia de Direito sem sociedade, e tampouco Direito sem sociedade. Nas palavras de Nader (1994, p. 298):

A sociedade sem o Direito não resistiria, seria anárquica, teria o seu fim. O direito é a grande coluna que sustenta a sociedade. Criado pelo homem, para corrigir a sua imperfeição, o direito representa um frande esforço, para adaptar o mundo exterior às suas necessidades da vida.

Tem-se, pois, que o Direito é um fenômeno social.

Sendo fenômeno social, que instrumentos possui que controlam a sociedade?

Ora, o Direito cria o Direito. Somente o Direito diz o que é ou não Direito. Através de seu código binário seleciona seus elementos autorreprodutivos e autorreferencias e dita as normas das comunicações internas deste subsistema, que vão guiar a sociedade.

Posto isto, cabe questionar: qual é o meio de comunicação interna do Direito? Salvo melhor juízo, pode-se dizer que é o sistema jurídico.

Neste viés, registra-se que o sistema jurídico é integrado pelas normas e atos jurídicos, pelo procedimento, pelos processos decisórios jurídicos (que podem ser três: processo legal de eleição política, processo legislativo e processo judiciário propriamente dito); os quais, articulados entre si, possibilitam o fechamento operacional na medida que se autoproduzem e autorregulam.

Dos ítens que compõem o sistema jurídico e acima relacionados, selecionam-se as normas, a fim de estudá-las de forma mais específica.

$\mathrm{Na}$ teoria dos sistemas, as normas para Luhmann (1983, p.57), são:

expectativas de comportamento estabilizadas em termos contrafáticos. Seu sentido implica na incondicionabilidade de sua vigência na medida em que a vigência é experimentada, e, portanto, também institucionalizada, independentemente da satisfação fática ou não da norma. O símbolo do 'dever ser' expressa principalmente a expectativa dessa vigência contrafática, sem colocar em discussão essa própria qualidade - aí estão o sentido e função do 'dever ser'.
Normas jurídicas são regras de condutas, parâmetros para o agir do homem em sociedade, ou ainda, podem ser consideradas processos de comunicação determinados pela oposição entre o lícito e o ilícito. Seguindo esta lógica de pensamento, é possível concluir que o Direito não ilide a prática do ilícito, mas tão somente, o prevê. Assim sendo, cabe questionar: como surge a norma?

A respeito, Eros Grau apud Theodoro Júnior (2007, p.16), in Revista de Processo, diz:

A norma é construída pelo intérprete, no decorrer do processo de concretização do direito (o preceito jurídico é uma matéria jurídica que precisa ser trabalhada). Inicialmente caminhamos no texto da norma até a norma jurídica. Em seguida, caminhamos da norma jurídica até a norma de decisão, aquela que determina a solução do caso. Apenas então se dá a concretização da norma, ou seja, mediante a produção de uma norma jurídica geral, no quadro da solução de um caso determinado. Assim, a concretização envolve também a análise do âmbito da norma, entendido como tal o aspecto da realidade a que respeita o texto. Dizendo-o de outro modo: a norma é produzida, no curso de processo de concretização, não a partir exclusivamente dos elementos do texto, mas também dos dados da realidade, à qual ela - a norma - deve ser aplicada. Ora, desde o momento da elaboração do texto até o instante de sua aplicação, a norma é determinada histórica e socialmente. Logo, quando o jurista cogita dos elementos e situações do mundo da vida sobre os quais recai determinada norma, não se refere a um tema metajurídico. A norma é composta pela história, pela cultura e pelas demais características da sociedade no âmbito da qual se aplica.

Para alguns autores, a norma é expressão da vontade humana, enquanto, para outros, é necessário conjugar à vontade diversos fatores externos e internos, tais como: cultura, evolução da sociedade, comunicação, poder.

Portanto, qualquer fenômeno é importante ao analisar o surgimento da norma, vez que, como elemento de um sistema fechado, é condição essencial considerá-la inserida no contexto. No entendimento de Coelho (1992, p.01):

A elaboração mental de que resulta uma norma jurídica não tem por base apenas a vontade dos homens concretos que a desenvolvem, mas encontra 
em fatores materiais, independentes daquela vontade, condicionantes que atuam de modo decisivo.

Acrescenta-se, também, que as normas não são criadas apenas por pessoas que integram uma comunidade jurídica, mas por todos que fazem parte da complexa sociedade, tidos como homens concretos, os quais, por meio da ideologia e da cultura, influenciam à norma no momento em que expressam sua vontade, via comunicação. (COELHO, 1992).

Apropriada é a opinião de Montoro (2000, p. 305), que ao conceituar norma, diz: “... é uma regra de conduta social. Seu objetivo é regular os homens em suas relações sociais".

Tomando o gancho das relações sociais, é importante dizer que as normas datam dos primórdios, mesmo que não efetivamente positivadas e sobre o assunto, transcreve-se o pensamento de José Augusto R. Pinto (2003, p.19):

Sociedade e Direito atuam como valores intercomplementares, o Direito a permitir à Sociedade que exercite seu irrequieto talento de mudar a criação, a Sociedade a consentir que o Direito exercite a serena prudência de modelar as mudanças.

Normas conferem unidade ao sistema permitindo que o Direito se autorregule e autoproduza.

Atualmente, sabe-se que a modernidade trouxe à sociedade possibilidades infinitamente maiores do que as probalidades previstas, tornando possível que os resultados das ações sejam, muitas vezes, diversos das expectativas.

Assim, o Direito emerge no intuito de estabilizar as expectativas, bem como para delimitar os limites de ação desta sociedade, moderna e complexa, e porventura, para neutralizar as ações através da sujeição às normas. Por outro lado, garante a cada indivíduo da sociedade a solução do conflito (acaso ocorra), por meio do devido processo legal. (LUHMANN, 1980).

Como já exposto, o Direito constitui-se através do condicionamento ou não às regras estabelecidas pelas normas jurídicas, as quais, via de conseqüência, geram decisões jurídicas.

Por sua vez, a decisão, no pensamento sistêmico de Luhmann, tem a função de absorver e reduzir a insegurança e para legitimá-la basta que se contorne a incerteza pela certeza de que a mesma ocorrerá. (LUHMANN, 1980).
Neste contexto, o Direito enquanto estabilizador das expectativas de comportamento é capaz de imunizar, bem como ditar regras por meio de seu código binário: direito/não-direito. Tem-se, então, o Direito como verdadeiro conformador dos indivíduos, na medida que positiva o que lhes é permitido e o que não é. (LUHMANN, 1983).

Ora, dentro do Direito, processos comunicativos válidos são determinados pela oposição entre o lícito/ilícito, como já dito alhures, e produzem elementos que operam insertos nestes pressupostos.

Nesta dualidade opositiva, os elementos de funcionamento tais como: leis, sentenças, jurisprudências, refletem a oposição, fazem referência e tensionam a si próprios. Por conseguinte, são pré-requisitos para elaboração de novas leis, novas sentenças, novas jurisprudências.

Ora, o Direito, enquanto sistema, é autorreprodutivo e autoproduz as suas próprias normas; por conseguinte, tudo o que não é lícito ou ilícito não integra o sistema, fazendo parte do entorno.

Segundo Bourdieu (2007, p. 209):

A ciência jurídica tal como concebem os juristas e, sobretudo, os historiadores do direito, que identificam a história do direot com a história do desenvolvimento interno dos seus conceitos e dos seus métodos, apreende o direito como um sistema fechado e autônomo, cujo desenvolvimento só pode ser compreendido segundo a sua dinâmica interna.

De outra feita, embora reconheça o entorno, o Direito opera a partir da construção própria dos sistemas organizados de produção, difusão e recepção de informações a fim de autoproduzir-se e autorregular-se. Ressalta-se, ainda, que a capacidade de produção dos seus elementos internos é a própria manutenção da sobrevivência. Na visão de Trindade (2008, p.120):

Proclama-se, nesse sentido, que as características determinantes de um sistema autopoiético são a sua autonomia em relação ao meio que o circunda e a sua clausura operacional no que diz respeito às comunicações com esse mesmo meio. A autonomia faz referência à observância do código binário que determina quais elementos pertencem ao sistema e quais são considerados alienígenas a esse. Esse código funciona na dualidade interno/ externo, excluindo os elementos que não possuam as características necessárias para serem aceitos 
pelo sistema. Essa seleção é feita por uma espécie de membrana que classifica quais conteúdos são, conforme as características intrínsecas do sistema, pertencentes à esse mesmo sistema.

Neste sentido, é possível dizer que o entorno, pode sim, irritar o subsistema Direito, desde que este permita haja vista que podem ocorrer situações externas, advindas da complexidade da sociedade moderna, que não encontrem guarida no referido códex. Esta possibilidade também foi prevista por Luhmann quando, em sua obra, teorizou acerca da "parábola do $12^{\circ}$ camelo".

É possível concluir que o Direito pode sofrer alerações, desde que, dentro de seus próprios limites. Sendo assim, o Direito se (auto)organiza por meio de seu código binário, criando e (re)criando o Direito. Caracterizada está a autopoiesis do Direito e sobre o assunto, manifesta-se Trindade (2008, p. 124) :

O sistema jurídico, sob a ótica da autopoiese, e seguindo os ditames dessa, pode ser considerado como um sistema ao mesmo tempo aberto e fechado. Aberto às influências do meio externo que passam pelo processo de seleção realizado pelo código direito/não direito, juridicizando os elementos do meio que passam a integrar sua estrutura e servem de aparato para a manutenção da sua auto - referencialidade. Fechado no sentido de auto - referencialidade operativa, isso é, o direito se auto - regula através da sua identidade (código binário).

Ora, Direito e a teoria luhmanniana estão interligados. Aplicar os pressupostos daquela ao Direito implica considerá-lo como resultado de inúmeras formas de comunicação, dotado de um código binário próprio, que dispõe o que é direito e o que não é. Em outras palavras, o Direito autoproduz seu campo de atuação por meio de códigos que entabulam o que faz ou não parte de sua comunicação, portanto, o Direito é autopoiético.

A respeito do exposto e convergindo com o entendimento de Luhmamn, Benjamim Zymler diz que o Direito, por possuir operações autorreferentes, ou seja, que funcionam de forma autônoma, é considerado um sistema autopoiético. Profere, também, que os ciclos autorreferenciais de comunicação no âmbito do subsistema jurídico - quando interligados - geram a autopoiese. (ZYMLER, 2002).
Desta feita, ao empregar os sistemas ao Direito, Luhmann consegue reduzir a complexidade social e o Direito, em seu viés autopoiético, se recria com base nos seus próprios elementos. Sua autorreferência permite que o Direito mude a sociedade e se altere ao mesmo tempo, movendo-se com base em seu código binário. (TRINDADE, 2008).

Vale acrescentar que a autopoiese do Direito e a constante relação comunicativa deste com o meio social, também chamada de acoplamento estrutural, torna premente a existência de uma Constituição, com o objetivo de canalizar todas as necessidades e expectativas humanas, quer sejam no âmbito social, político ou jurídico. (TRINDADE, 2008).

Assim, neste ponto de desenvolvimento do presente trabalho aborda-se (em breves comentários e sem qualquer intenção de esgotar e/ou aprofundar o tema), sobre a Constituição e a ligação desta à teoria sistêmica de Luhmann, tão somente sob as referências dos sistemas jurídico e político.

Sob a ótica jurídica, a Constituição é um texto autológico pois prevê a si mesmo como parte do sistema jurídico. Assim, a Constituição confere fundamento ao Direito na exata proporção em que fundamenta-se em si mesma (SIMIONI, 2009).

Estabelece, também, a diferença entre algo constitucional e algo inconstitucional, diferenciando-os da distinção entre ilegalidade e legalidade. Consoante Luhmann apud Simioni (2009, p. 316):

Assim, não apenas os fatos - que só poderiam ser
tratados na forma legal/ilegal - mas, agora também
todas as normas jurídicas....Nessas condições, o
direito conquista reflexidade. Ele passa a refletir
sobre a sua própria correção normativa e sobre a
sua própria validade formal. Sob a distinção entre
constitucional e inconstitucional, as Constituições
permitem o julgamento do direito/não-direito, do
próprio direito.

Partindo desta perspectiva teórica, na visão de Luhmann, a Constituição tem a função de resolver os embates, na medida em que positiva normas. Ademais, para o autor, pode ser considerada como uma forma de comunicação entre o Direito e a Política, servindo como referência as mesmas. (LUHMANN, 1983).

Neste sentido, para Trindade (2008, p. 89) a Constituição: “....serve de elo entre o sistema jurídico e o político, juridicizando relações políticas e 
mediatizando juridicamente interferências da Política no Direito".

Esta construção analítica confere à Constituição um fundamento político, enquanto vista no âmbito do Direito. Por outro lado, se analisada sob o prisma da política, a Constituição tem um fundamento jurídico. Sobre o assunto, transcreve-se a opinião de Simioni (2009, p.319):

A Constituição serve, assim, de fundamento político pra o direito e, ao mesmo tempo, de fundamento jurídico para a política. Por isto, a Constituição constitui um elo de ligação entre direito e política, quer dizer, constitui um meio que recepciona formas de acoplamento estrutural.

Tem-se, portanto, que a Constituição é um meio limitador das influências comunicáveis entre a Política e o Direito.

Sobre o assunto, profere Simioni (2009, p. 323): "a Constituição produz soluções políticas para o problema da autorreferência do direito e soluções jurídicas para o problema da autorreferência da política". Ou seja, a Constituição além de servir como referência externa tanto à Política quanto ao Direito, participa da autopoiese de ambos.

Aliando à afirmativa de Luhamn apud Pedron, resta registrar que a Constituição é o vetor do código binário ou meio de acoplamento estrutural entre Direito e Política, permitindo fechamento do Direito por meio do seu reingresso no sistema. (PEDRON, 2004).

\section{Considerações finais}

Todo o delineamento deste estudo resulta no entendimento de que complexidade da sociedade moderna evidenciou a necessidade do desenvolvimento de um estudo diferenciado e específico. Assim, o sociólogo Niklas Luhmann despontou, ganhou relevância e sua sagaz visão, desenvolveu particular forma de pensar a Teoria dos Sistemas.

Esta, por sua vez, através de conceitos e pressupostos básicos possibilitou que os sistemas sociais fossem divididos conforme suas especificidades. Não obstante, é um instrumental de importância ímpar a fim de compreender o Direito.

Em face da análise teórica, da historicidade e da interpretação do fenômeno que é o pensamento sistêmico luhmanniano demonstrou-se que esta teoria não é superficial, mas sim, um aporte universal para compreender tanto a sociedade quanto o Direito, e ainda, tantas outras áreas (que não foram mencionadas por este artigo, vez que não se tinha como meta abranger todos os embates que o tema possibilita).

Em suma, ao analisar o Direito correlacionando-o à teoria dos sistemas constata-se que aquele se cria e (re)cria baseado em seu código binário: direito/não-direito. Ademais, retratou-se, no bojo do presente texto, que o Direito é um subsistema fechado que se autorregula e autoproduz, no intuito de estabilizar as expectativas humanas. Por conseguinte, a Constituição - vista como meio limitador entre a Política e o Direito - tem o objetivo de canalizar mencionadas expectativas.

No arremate, é necessário mencionar que após estudar o pensamento sistêmico Luhmanniano e a ligação deste com o Direito, enquanto sistema social, muito além de vislumbrar uma ligação entre ambos, é possível concluir que a entrada da sociedade para a modernidade, a comunicação, entre outros fatores; são determinantes à criação da norma, a qual integra o subsistema do Direito, que é fechado, autorreprodutivo e autorreferencial, ou seja, autopoiético.

\section{Referências bibliográficas}

BOURDIEU, Pierre. O poder simbólico. Tradução Fernando Tomaz. 10 ed. Rio de Janeiro: Bertrand Brasil, 2007.

CHAI, Cássius Guimarães. Descumprimento de preceito fundamental: identidade constitucional $e$ vetos à democracia. Belo Horizonte: Mandamentos, 2004.

COELHO, Fábio Ulhoa. Direito e poder: ensaio de epistemologia jurídica. São Paulo: Saraiva, 1992.

CORREIA, João Carlos. Os mass media entre o sistema e o mundo da vida. Universidade Beira do Interior. Portugal. Disponível em http://bocc.ubi.pt/pa/correia-joao-carlosmass-media-mundo-da-vida.html.

FEDOZZI, Luciano. A nova teoria de sistemas de Niklas Luhmann: uma leitura introdutória. In: NEVES, Clarissa Eckert Baeta; SAMIOS, Eva Machado Barbosa (Org). Niklas Luhmann: a nova teoria dos sistemas. Porto Alegre: Universitária, 1997.

LUHMANN, Niklas. A realidade dos meios de comunicação. Tradução de Ciro Marcondes Filho. 2.ed. São Paulo: Paulus, 2011. 
LUHMANN, Niklas. Legitimação pelo procedimento. Tradução de Maria da Conceição Corte-Real. Brasília: Universidade de Brasília, 1980.

LUHMANN, Niklas. Sociologia do Direito I. Tradução de Gustavo Bayer. Rio de Janeiro: Tempo Brasileiro, 1983.

MARIOTTI, Humberto. As paixões do ego: complexidade, política e solidariedade. São Paulo: Palas Athena, 2000.

MATURANA, Humberto; VARELA, Francisco J. A Árvore do Conhecimento- As Bases Biológicas da Compreensão Humana. São Paulo: Palas Athena, 1995.

MONTORO, André Franco. Introdução à Ciência do Direito. São Paulo: Editora Revista dos Tribunais, 2000.

NADER, Paulo. Introdução ao estudo do Direito. 9.ed. Rio de Janeiro: Forense, 1994.

NEVES, Clarissa Eckert Baeta. Niklas Luhmann e sua obra. In: NEVES, Clarissa Eckert Baeta; SAMIOS, Eva Machado Barbosa (Org). Niklas Luhmann: a nova teoria dos sistemas. Porto Alegre: Universitária, 1997.

PEDRON, Flávio Quinaud. Direito, Política e Constituição para a Teoria dos Sistema de Niklas Luhmann. Disponível em: http://www.mundojurídico.adv.br. Acesso em 15 de maio de 2011.

PINTO, José Augusto Rodrigues. Sociedade e Direito o Equilíbrio Vital dos Opostos. Novo Curso de Direito. São Paulo: LTR, 2003.

SEVERINO, Antônio Joaquim. Metodologia do Trabalho Científico. 21. ed. São Paulo: Cortez, 2000.

SIMIONI, Rafael Lazzarotto. A Constitucionalidade da Constituição em Niklas Luhmann: paradoxo e contingência do Direito Constitucional na sociedade globalizada. In Revista de Direito Constitucional e Internacional. São Paulo: Revista dos Tribunais, 2009.

THEODORO, Humberto. Revista de Processo. São Paulo: Revista dos Tribunais, 2007.

TRINDADE, André Fernando dos Reis. Para entender Luhmann e o Direito como Sistema Autopoiético. Porto Alegre: Livraria do Advogado, 2008.

ZYMLER, Benjamin. Política e Direito: Uma Visão Autopoiética. São Paulo: Juruá, 2002.

Artigo Submetido: 20/04/2012

Artigo Aprovado:13/09/2013 